岩

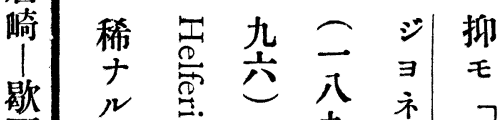

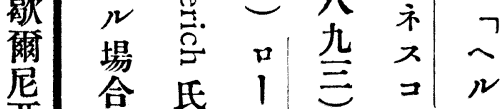

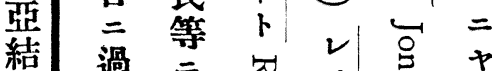

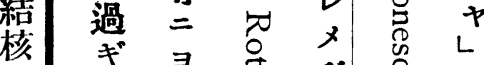

人

例

二 就全九 气九就

梁梁另宍节二キ

ク論兵者こテ

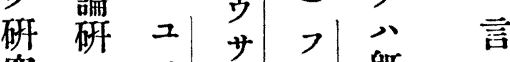

究 $三$ 제 既

ス 亚 $千$ 学

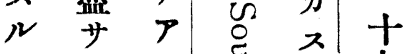

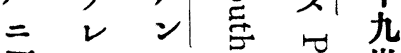

價 今

七

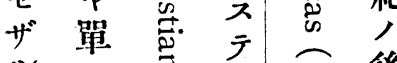

緒

O

$\nu=J \approx$ 後

モ 汎 ブ| ンั

, 發ラ心九二

ナ性, 光元於

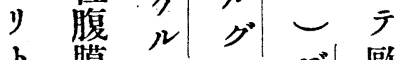

卜 膜 借ブ歐

看結

做核 只

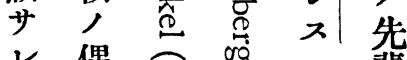

然 二禺告輩

尔九公壳例

ガへ九九 九

岩

姬 テ

歇

爾 原

路

病

院

明

治

四

十

四

如

予

崎

年

十

九丕囊劣

㒻幸絛

衛

月

シ 發怘官 グ

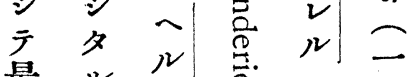

最年年究公

近比 三穿分

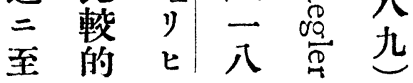


現 又淽 來生遺 既

症間、少来傅 待

モ 硬堃健菜

ナ强結 水 因

一 ク, 核, =

見自感, 麻 徵治

入然 $P$ 診疹

N = リ迦 7 可十

二消食 $\exists$ 經 $\neq$ 四

體退慾 受過事年

格ス進ク七ナ空(二)

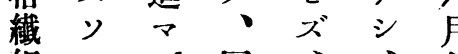

細, $x^{\circ}$ 同!

跡殆年明同 日

貧二冬治胞初

奥章之期 西言診

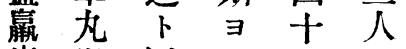

瘦肾同り三个

七外時八年》男

y = 期稍五其十

$\therefore$ - $\exists$ 輕月中八

胸箇少快 $\exists \div$ 年

部人在 $\exists$ 人。

奋㓌覺漸 入

檢豆露工次六

ス大根夕京葴

硬部り弱人

二結 二 シ 、時

左物時 ガ 咳 腹

肺 7 越嗽部 尖觸膨工盜,

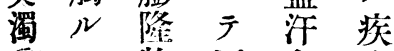
音、物四食病 - 7 十志 $=$ 呼見生四不 氣光哖 振 リ

延卜 天 三等 死 長。不司, 的

快頃殕他

小, $\exists$ 碍,

水感り

泡学胃發

音少部 ス 健

可停 故 金

聽 此 灣二广

ク 當り

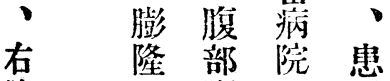

名肺尘膨 二悬
記 牀後レリニリル

シ上剖 バ此 そ一迄

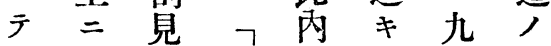

$\neg$ 證 $一$ 比五 $\bigcirc$ 泰

一明際ル較十三西

$ル 七 シ=$ 的四年,

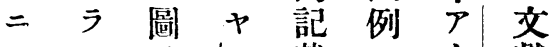

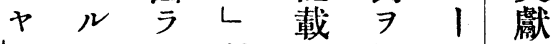

ட、ズ結見べ 症, 發核備夕心悉 二域見 $ン リ \gg 》$ 就二七稀ル上总涉 實 キ達う有モ云吕獵 特七レ十, 人 殊ザタル五り獨ル ノルル疾、!逸コ 與 $カ ゙ モ$ 患他本國卜 味如, 公邦二

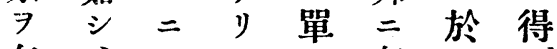
有、シ $、$ 在 $テ{ }^{*}$ 七予 テ言追学信卜 ル頃手フ加硔 ズ踓 士 $\frac{6}{1}$ 術 $心$ 明 $ン$ 三漞 前 事 或 治二一 資 ク 二 實 $\therefore$ 足八 七治本三附市少九 ン 驗 症 近記兵十一 卜七 欲ル診・ル池例ブ ス本嵫且, 畐 $7 ル$ ○症七本ミ民集ン , 㾚 = 初又 一人 分的獨自 例例多于 一逸個 $\exists$ 八刀詳例國, 有更一細学以一 ス $=\neg 7$ 公外例 、稀 敢ナル禁方於 加 早 = ズテ方 新、ヤ、沗、テ 面 節 ᄂ 是り價士 目于根兰總值三

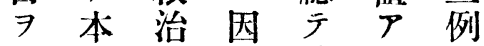
見症手り八在 ズ 八術厅例或報 卜 未文之 踓 父 $\ni$ 得 價 テ 略 臨 死 觀 夕 值 $\exists$ 


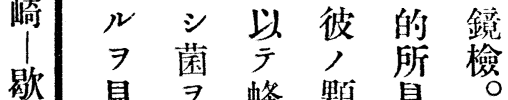

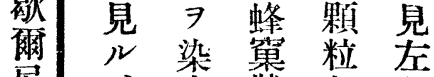

惡 肥 出 牀部記 摘

出墰 氏

核 厚出區正如 此 $大$ 壁

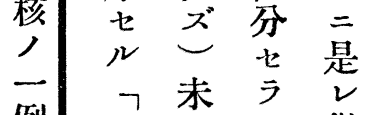

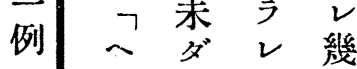

二就乾 タ 多

就 二酪ル,

ヤ變 各 結

ᄂ 生 简 核

囊 八 結 結

壁 認 節 節

$=$ 厶中,

於ル二密

$\bar{\gamma}=\cdots=$

八足固 集

其 亏 有 合

結ザ, シ

締 ル核 テ

織 程 配一

度 置 見

增ノ

殖上有巴

著皮 ス腺

樣光,

ク 細 巨造

血胞大 構

管 及 細 二

八 小胞 髫

增 圓, 䯳

加 形 - 夕

シ 細 筒 ル

壁胞 万歹

尘至,

九盟 周 筒 シ

百扫圍ノテ

十 9 中 少

一、圍 心 許

小繞 二,

圆 泣 結

形浸 三 締

細 潤 $\frown$ 織

胞七但 $\Rightarrow$ $\neg \stackrel{1}{=}$ 周

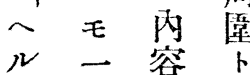

二简爷痤

中, 大着

ᄂ 硬網

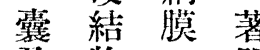

及物 二 盟

内

容y $\overline{\text { 肥 }}$

辰中厚

ᄀ襄三

于算品

王 队内人

然

余面少少如

隆夫淡

起恰黄

封 天毛色

襀、淋透

ᄀ精巴明

系腺液

筮樣

卜葫会

₹华圆会

稍 $\neq$ 、

”栯硬囊

土也物内

才り面

シ ○ y,

ㄴ. 此

大 大䡬

染網的

色, 滑

、尖澤

其蹦

顯公

微

鑲
底 發
囊 テ
檿結

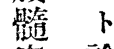

手在音其右 前

術向尖鼠面 所呈端蹊 八 見 二 部第 六 二、小 卧指 檢 肋 根九少位頭 $九$ 骨 手病 $\exists$, 術 院

其 十 結 り彈 際日核 2 軟 時 面 於工茫罢二於局 ケ十側太筒亏 胛 化外及, 右下 肉デ 鼠副硬鼠角 眼 ル蹊 峷 結 蹊 以 的り：歇九物外下 所 2 爾 $=7$ 輪 濁

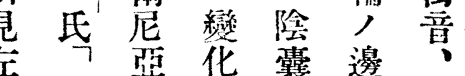
不二ナ皮业呼 如 ボ シ 下リ吸 ラテ

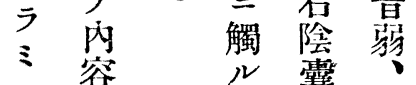

ン 㚇

王恐

峌

泉名

衤大

ビ| 網

1 膜

ル

氏

腰ン

麻馀

醉 衒

、 二 腹

素 亘 部

$\exists$ タ

リリ異

移 常

動 緊 ナ

性 張 シ

ナ性、

リ圆 檢

、錐 尿

膨 形 蛋

隆 隆 白

部 起 ナ

不少

透波

明 動

$=$ 7

シ 呈

テ ᄌ 
至載省原本女稀頻試 以 大 便七ン六比八次 宜り等本例 シ 緒元欲 ᄀ

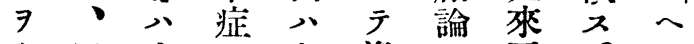
興日本公九遥二吾○ル 人夕聇果歳力於人 = 或へ著 八原二嘍心゙ 箱二キ發王多为

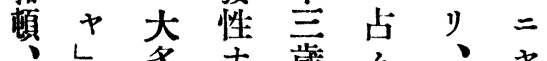
巧囊數光咸台本 ᄂ 十公三力, 而症ナ 亏腹於將男 シ八化

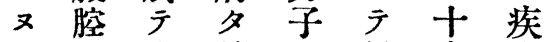
還, 腹續二男藏病

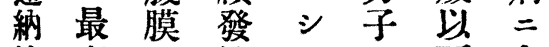
法底, 性亏宁會 部限子悉鼠, 入

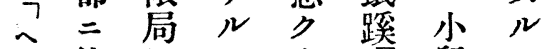

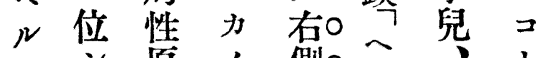
二 愿, 侧。 血發疑鼠江, 液性問蹊市至意

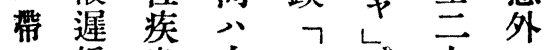
, 緩患古へ下=

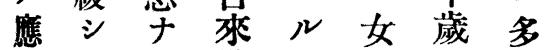
用易り議二子手丝 乃铪中兵二 至一 其简其焦, 少 他分有點場年亏 ，洞北大合 $\nu=$

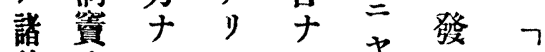
外子ルキy次

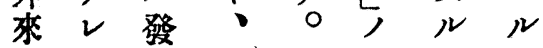
器 ゙病ル場コこ

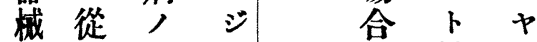
的理 $中$ 亦最 ᄂ 刺胄儿大毛結 载細 $\mathrm{r}:$ 八菌 炎界寻寻界比 症潜次衣示男较 状, 중 發三記： $\overline{+}$

L.

結（三）

核

評

關

入 諭

s

齐

獻

$=$

徵

次

广

得

夕

ル

智

墥

F

總

括

的

$=$

記

載

シ

县

予

自

驗

$=$

鑑

ミ

广

紫

天性 的

評

論
ズ殘八經 八 食り日過沉 味 三 拢。發 ナ 硬 絲

結、兵 $=$ 卜 八月浸 云先干十潤 几達七日 リ寻午ル ○リ第 後 $モ$ 消 - 輕 特 失期度二 㾮, 血 右合惡管 陰寒外 露 全圍 二治 $y=$ 八退體顯 何院溫 等 等 其分东 膨後度 諸 隆, 九所 - 經 分 $=$ 疼過、上 痛 三 六記 等 就 月 結 , $\neq$ 十 節 障 广一同 碍 八 日 樣 F十以, 覺 月 後阌 工發花 ズ 干熱 胸九七呈 部日ズ七 $\therefore$ 附、次 通秝十部 常書亲分 $ナ=$ 日 儿依初》。

モ $v$ 女

胃 バテ

腸手便

未 術 通

ダ 後 ア

全基 y

快跡、

$七=十$ 
5 號 二十六百二第

岩

崎

囊 病ノ二核年バタ例リザテ根モモ低起

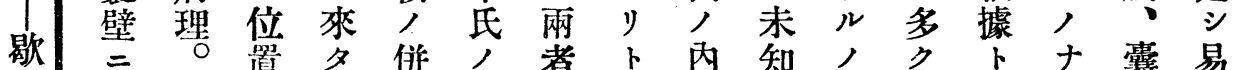

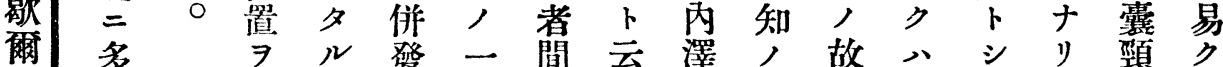
尼多

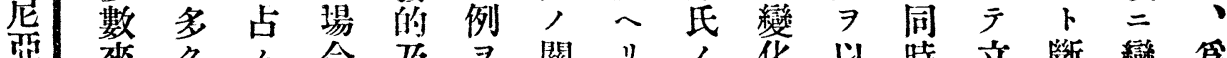

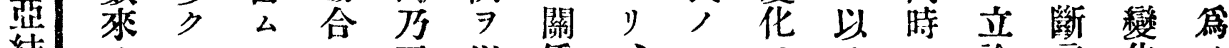
結り 八ル, 至以係、一

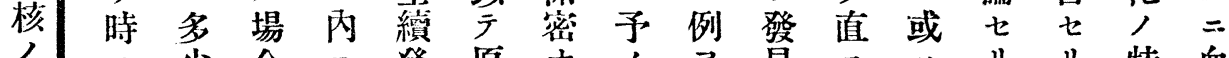

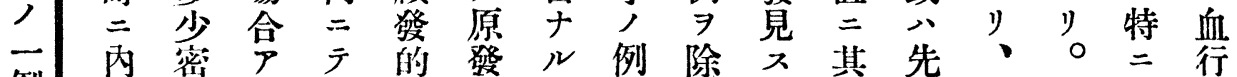

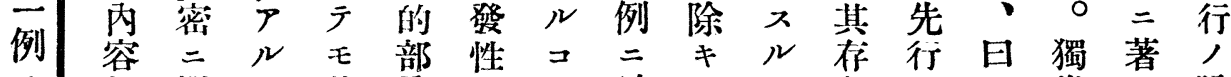
二圽 撒 可其 分

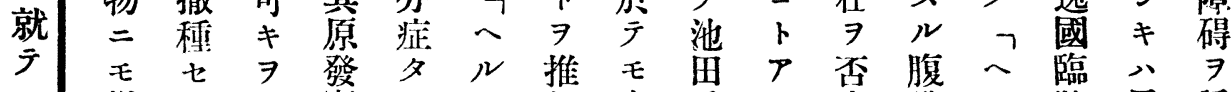

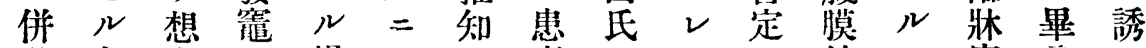
發灰修人場ヤ不者八バス結二家竟七

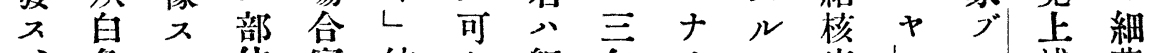
、色ル位實結ク既年りコ症しル述菌

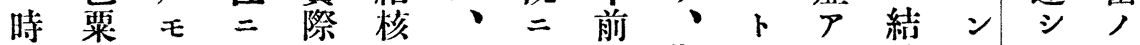

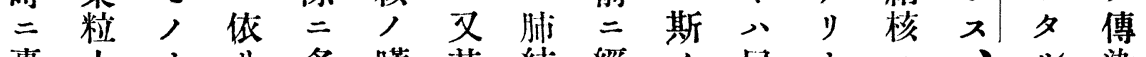

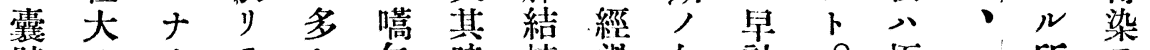
壁人yテ爫時核過如計 八小

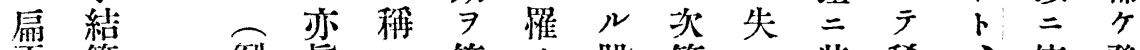

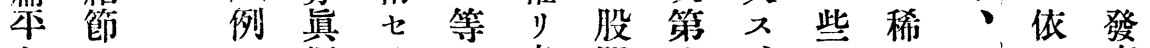

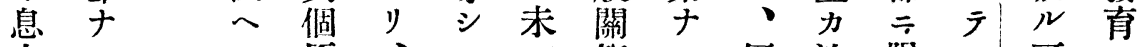

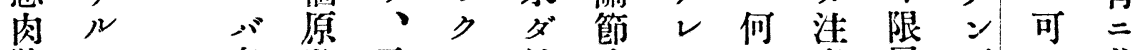

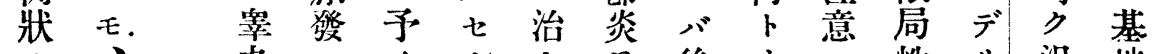
八 丸 肥屡、ル 知 $サ ゙$ 擧者レ可原七發

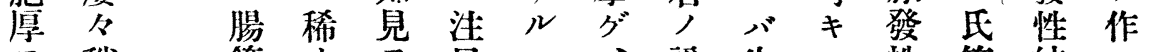

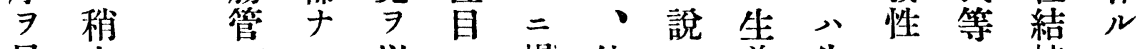

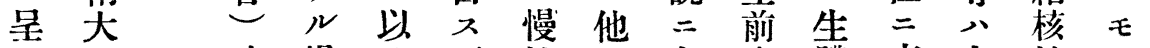
ス 時場 テ 可性心左病體來之性,

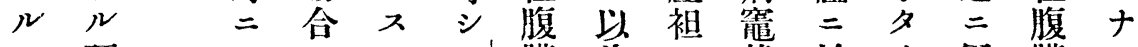
二硬 一 ノ レ ト膜前 ス 㫮於り区膜り

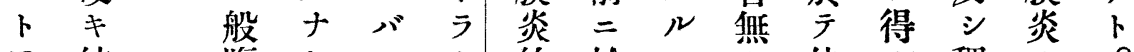

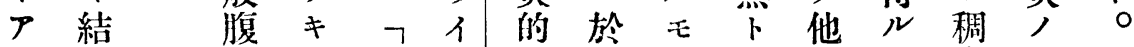

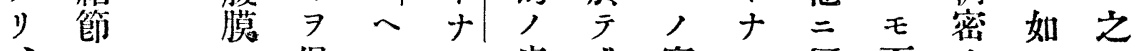
九 以 集 比セ保 ル 百上合 シ

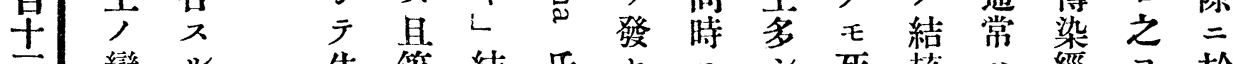

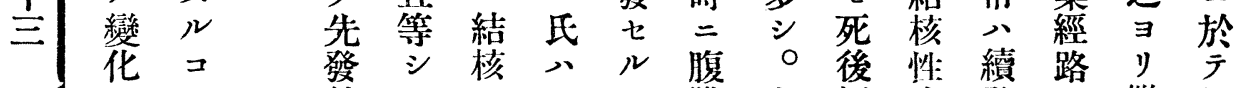
八卜 的ク八- $、$ 膜本解症發人繼見 特 $>$ 好彎腹九少炎邦剖狀性研發心

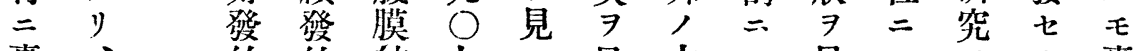
囊、的的結七ル見六ヨ見シ $ン$ 囊 


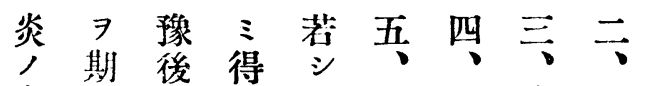

合ス 0 出 以厴囊囊别

併可 時上二壁壁二

症り予六分占證 夕、蓋所》顆文 不 $ル$ 繳 特 息腹粒 八可 二發二之二腔状壁 $\neq$ 際的本 $\exists$ 加 $卜$ 肥㐫原

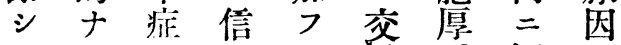
テルノジ通○觸ナ 八場診テニ自的 一 合 逐譟 現 在 般 二 リ二ナ 二テ重少著 ル 不モキ名朋腹 良唒 $\ni$ 十, 水 夕水置力腹, ル他クラ膜存 ，人所 ン 結 在 免腹背平核

\section{$\nu=$ 實}

ザ 先 二

ル發预

可 $七$ 後

シ $v$,

○場大

合

, 關

如 $ᄌ$

$\neq$ ル

$>P$

倘 レ

ホバ

可ナ

良少

期 装

ス シ

可 原

ク 發

䚁 七

$=$ r

結 際

核 =

性 八

腹 奎
可 シ

キ テ

硬 時

結 \&

物 發

八 秝

存 万

微
任 ル
一見診診 見

性從 バ,
頸

部

來本困腸

還 症 難 本 管 底

納, 二看声之部

容存 $シ==$

易 在 于 就次發

ナ 7 充 キ グ

り疑分学・易

シ 7 , 之

モテ確記 敦、

ノ可信 載 要 膿

二ナ 末 $末$ 演

比り手多ル，

較、術甚二形

的日二ダ一成

色夕先多般七

速、于腹 引

二 テラ膜 ル

T下 ズ結。

但 推核口

得, 卜

此势 テ 變

人化为

際忍, 、

不 如洼選 内

完 济年

全卜 $\Rightarrow$ 所,

性踓勃十。虚

篧予起 $\neq$ ナ

頓 七 ナル

卜 知ザリコ

區見ル人下

别

セ

$\exists$

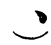

或

徐

徐

$=$

楀

夕

ル

不

還

納

以 - y

于 而

ス 特

ᄂ 異

多

バ

次 根

述據

为

容

卜

シ

テ

主夕

要

點 本

于 症

弡,
大

網

膜 


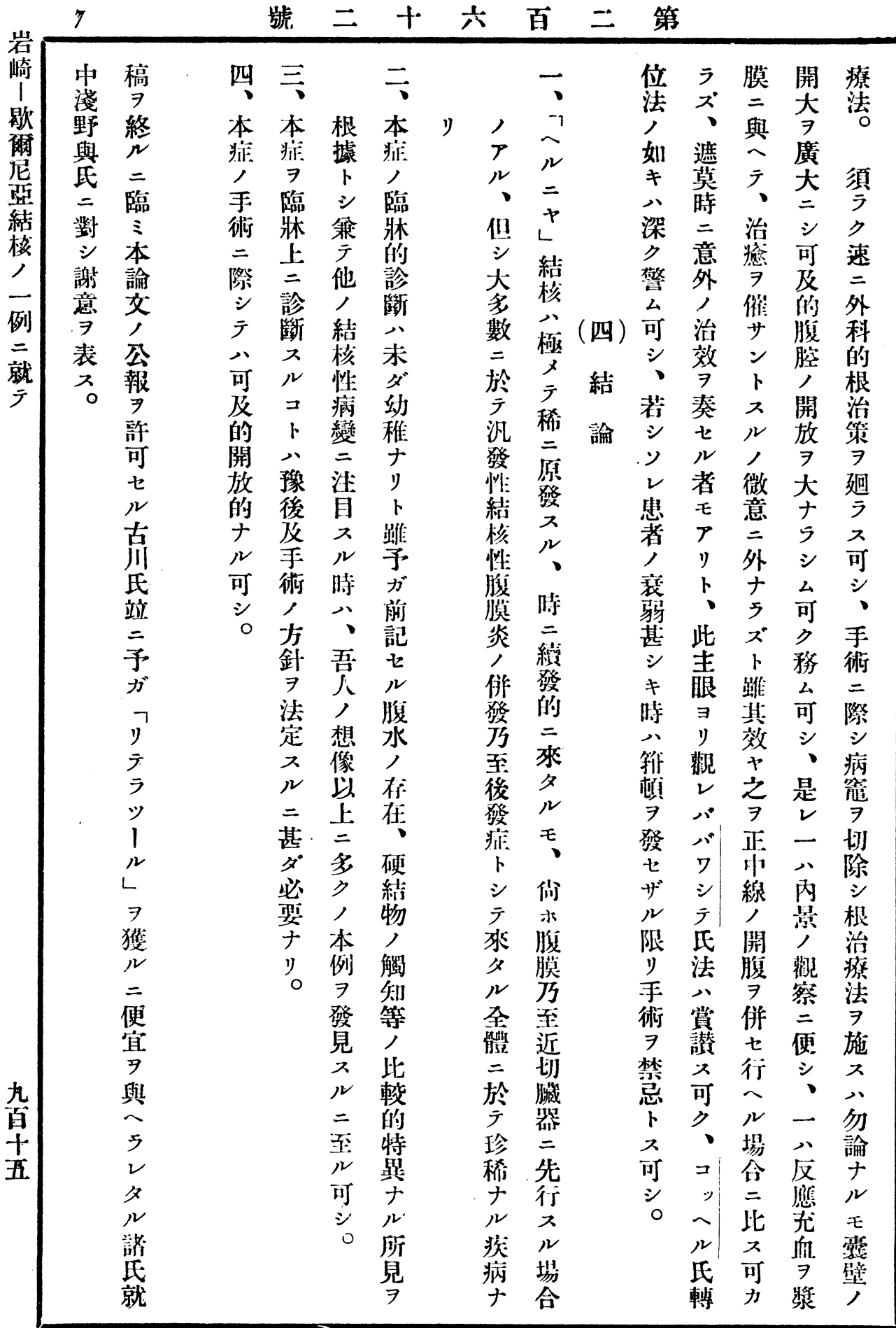


號 二十六百二第

\{
\{
\{
\{
\{
\{
\{

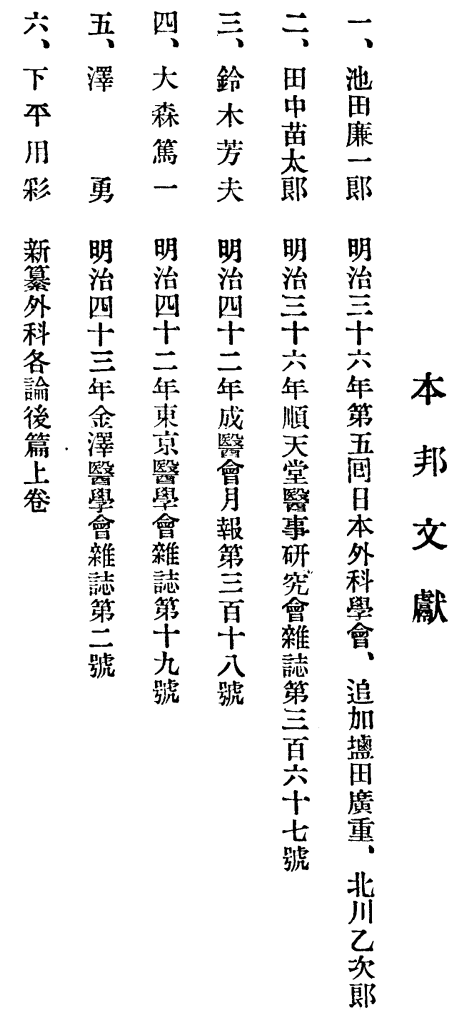

